\title{
GAMBARAN LESI TRAUMATIK MUKOSA MULUT PADA LANSIA PENGGUNA GIGI TIRUAN SEBAGIAN LEPASAN DI PANTI WERDA KABUPATEN MINAHASA
}

\author{
${ }^{1}$ Angelia Langkir \\ ${ }^{2}$ Damajanti H. C. Pangemanan \\ ${ }^{3}$ Christy N. Mintjelungan
}

\author{
${ }^{1}$ Kandidat Skripsi Program Studi Pendidikan Dokter Gigi Fakultas Kedokteran \\ ${ }^{2}$ Bagian Fisiologi Fakultas Kedokteran \\ ${ }^{3}$ Program Studi Pendidikan Dokter Gigi Fakultas Kedokteran \\ Universitas Sam Ratulangi Manado \\ E-mail: angelia.langkir@gmail.com
}

\begin{abstract}
Removable partial dentures (RPDs) are artificial teeth that replaces one or more missing teeth in the upper jaw or lower jaw and can be removed by the patient. Elderly is an aging process that is experienced by everyone and can not be avoided by anyone. Traumatic lesions is a condition of discontinuity network extends from the dermis to the subcutaneous and always occurs in pathological conditions. His study aimed to describe traumatic oral mucosal lesions in elderly using removable partial dentures in nursing homes. This was a descriptive study with cross sectional approach. Social Institution used were Tresna Agape Tondano Elderly, Social Institution Ina I, Deborah Werdha Panti, Panti Yakobus Peduli Elderly, Elderly Nursing Hana, Tabitha Nursing Elderly and Elderly Nursing Pengasih. Samples were all elderly that used Most Removable Teeth. The results showed that the majority of elderly using removable teeth in Minahasa regency nursing homes have experienced traumatic lesions. Conclusion: Most of the elderly using removable partial dentures in Minahasa district nursing homes had experienced traumatic lesions caused by removable partial dentures.
\end{abstract}

Keywords: removable partial dentures, elderly, traumatic lesions.

Abstrak: Gigi tiruan sebagian lepasan (GTSL) adalah gigi tiruan yang menggantikan satu atau beberapa gigi yang hilang pada rahang atas atau rahang bawah dan dapat dilepas oleh pasien. Lesi traumatik merupakan kondisi diskontinuitas jaringan yang meluas dari dermis hingga ke subkutis dan selalu terjadi pada kondisi patologis. Tujuan Umum, untuk mengetahui gambaran lesi traumatik mukosa mulut pada lansia pengguna gigi tiruan sebagian lepasan di panti wredha.Tujuan Khusus, untuk mengetahui gambaran lesi traumatik mukosa mulut pada lansia pengguna gigi tiruan sebagian lepasan di Panti Wredha kabupaten Minahasa yang di tinjau dari lokasi lesi pada mukosa mulut. Jenis penelitian ini yaitu penelitian deskriptif dengan pendekatan cross sectional.Gambaran lesi ulseratif terhadap pengguna gigi tiruan sebagian lepasan pada lansia di panti werdha kabupaten minahasamenunjukkan sebagian besar pernah mengalami lesi ulseratif, dan yang terbanyak pada perempuan $(93,3 \%)$. Lokasi yang paling sering terkena yaitu lidah $(55,17 \%)$. Penyebab ulkus yang paling sering yaitu trauma bagian dasar/sayap GTSL $(62,1 \%)$. Lesi ulseratif terjadi dengan frekuensi tidak teratur $(68,9 \%)$. Responden paling banyak membiarkan ulkus tanpa pengobatan $(48,3 \%)$, sedangkan $51,7 \%$ responden mengobati sendiri dimana $73,3 \%$ diantaranya menggunakan obat topikal. Simpulan: Sebagian besar lansia pengguna gigi tiruan sebagain lepasan di Panti Wredha kabupaten Minahasa telah mengalami lesi traumatik.

Kata kunci: gigitiruan sebagian lepasan, lansia, lesi ulseratif 
Beberapa akibat kehilangan gigi sebagian lepasan yang tidak digantikan adalah migrasi dan rotasi gigi asli yang masih ada, erupsi berlebih, penurunan efisiensi kunyah, gangguan pada sendi temporo mandibular, beban berlebih pada jaringan pendukung, gangguan bicara, estetis yang buruk, terganggunya kebersihan mulut, atrisi, dan efek yang tidak diinginkan pada jaringan lunak. Fungsi gigi tiruan sebagian lepasan antara lain memperbaiki fungsi pengunyahan, memulihkan fungsi estetik, meningkatkan fungsi fonetik, serta mempertahankan jaringan mulut yang masih ada agar tetap sehat. ${ }^{1}$

Gigi tiruan ditinjau berdasarkan bahan gigi tiruan sebagian yaitu kerangka logam dan bahan akrilik. Gigi tiruan kerangka logam terdiri dari landasan gigi tiruan logam karena bahan logam cukup kuat, landasan gigi tiruan kerangka logam dapat dibuat lebih tipis dan lebih kecil sehingga pemakaian akan lebih nyaman. Bahan akrilik merupakan campuran bahan sejenis plastik, yang manipulasinya mudah, murah, ringan dan bisa diwarnai sesuai dengan warna gigi dan gusi. ${ }^{2}$

Lansia merupakan suatu keadaan yang dialami oleh semua orang dan tidak dapat dihindari oleh siapapun, namun manusia dapat berupaya untuk memperlambat penuaan. Lansia merupakan kelompok umur pada manusia yang telah memasuki tahapan akhir dari fase kehidupannya. Fungsi fisiologis tubuh pada setiap orang sangat berbeda, dalam pencapaian puncak maupun saaat menurunnya, namun umumnya fungsi fisiologis tubuh mencapai puncaknya pada umur 20-30 tahun, setelah itu fungsinya menurun. $^{3}$ Organisasi Kesehatan Dunia (World Health Organization) menggolongkan lansia menjadi 4 yaitu: usia pertengahan (middle age) 45 - 59 tahun, lanjut usia (elderly) 60 - 74 tahun, lanjut usia tua (old) 75 - 90 tahun dan usia sangat tua (very old) diatas 90 tahun. $^{4}$

Lesi traumatik merupakan kondisi diskontinuitas jaringan yang meluas dari dermis hingga ke subkutis dan selalu terjadi pada kondisi patologis. Pada umumnya, lesi ini disebabkan oleh trauma mekanis dan hubungan antara penyebabnya diketahui. ${ }^{5}$ Lesi traumatik tergolong lesi reaktif dengan gambaran klinis berupa ulkus tunggal pada mukosa yang dapat disebabkan oleh adanya trauma fisik atau mekanik, perubahan thermal, kimia dan radiasi yang mengakibatkan kerusakan jaringan. ${ }^{6}$

Penyebabnya lesi traumatik antara lain maloklusi, kesalahan pada pembuatan protesa, menyikat gigi yang terlalu keras, kebiasan pasien yang suka menggigit-gigit pipi atau bibir dan oralpiercing. ${ }^{1}$ Trauma mekanik dapat disebabkan oleh karena tergigit baik sengaja maupun tidak sengaja. Lokasinya bisa bersebelahan dengan gigi yang karies atau patah, tepi plat gigi tiruan atau ortodontik. $^{7}$

Lesi ditandai dengan membran fibrin purulen berwarna kekuningan yang disertai dengan timbulnya rasa nyeri. ${ }^{8}$ Menurut Neville tepi ulkus traumatik ditandai dengan area berwarna kekuningan yang dikelilingi oleh eritematous, namun pada beberapa kasus, tepi ulkus dapat berwarna putih karena adanya hiperkeratosis. ${ }^{9}$

Ulkus traumatik dapat terjadi pada lidah, bibir, dan mukosa bukal. Selain itu, dapat juga terjadi pada gingiva, palatum dan fornix. Lesi ini dapat sembuh dalam beberapa hari atau minggu setelah penyebab traumanya dihilangkan. Rasa nyeri akan hilang dalam dalam waktu 3 atau 4 hari, dan akan sembuh dalam jangka waktu 10-14 hari. Jika ulkus tidak sembuh dalam kurun 2 minggu, maka diindikasikan untuk dilakukan biopsi. $^{10,11}$

Gigi tiruan sebagian lepasan dapat menyebabkan trauma pada jaringan keras maupun lunak di bawah gigi tiruan. Perubahan ini mulai terjadi segera setelah pasien memakai gigi tiruan dan mencakup bagian peradangan mukosa yang cukup tinggi dalam satu tahun sejak gigi tiruan dibuat. Pada gigi tiruan lengkap yang baru, yang secara klinis kecekatannya baik, belum 
menjamin bahwa peradangan mukosa tidak akan terjadi. Pemakaian gigi tiruan sehari semalam untuk waktu yang lama dapat menyebabkan timbulnya lingkungan mukosa yang menerima beban berat mengunyah, terutama bila terdapat pula kebiasaan menyentak gigi. ${ }^{12}$

Efek buruk dari trauma kronis yang berbahaya dari pemakaian gigi tiruan cukup banyak dilaporkan. Penelitian akhir-akhir ini juga menemukan infeksi jamur misalnya candida sebagai unsur yang menunjang timbulnya perubahan patologis yang berkaitan dengan pemakaian gigi tiruan. Beberapa hal lain yang menunjang timbulnya perubahan patologis yaitu perubahan nyata dalam kestabilan lingkungan di dalam mulut, traumatik dan infektif atau keduanya akan meningkatkan resiko berkembangnya proses patologis. ${ }^{12}$

Lesi traumatikmerupakan suatu bentuk perubahan yang bersifat patologik akibat pemakaian gigi tiruan di dalam rongga mulut ditandai dengan adanya ulkus tunggal pada mukosa ditepi plat gigi tiruan lengkap ataupun gigi tiruan sebagaian lepasan baik pada rahang atas maupun rahang bawah. ${ }^{13,14}$

Lansia merupakan suatu keadaan yang dialami oleh semua orang dan tidak dapat dihindari oleh siapapun, namun manusia dapat berupaya untuk memperlambat penuaan. ${ }^{15}$ Lansia merupakan kelompok umur pada manusia yang telah memasuki tahapan akhir dari fase kehidupannya. Pada kelompok yang dikategorikan lansia ini terjadi suatu proses yang disebut aging process. ${ }^{4}$ Penuaan adalah suatu proses menghilangnya perlahan-lahan kemampuan untuk memperbaiki diri dan mempertahankan struktur dan fungsi normal sehingga tidak dapat bertahan terhadap infeksi serta memperbaiki kerusakan yang dialami. Kehilangan gigi pada lansia dapat digantikan oleh gigi tiruan, yang seringkali menyebabkan timbulnya lesi traumatik pada jaringan lunak rongga mulut. ${ }^{4,16}$

Berdasarkan uraian di atas penulis tertarik untuk meneliti tentanggambaran lesi traumatik mukosa mulut pada lansia pengguna gigi tiruan sebagian lepasan di panti Wredha kabupaten Minahasa Induk.

\section{METODE PENELITIAN}

Jenis penelitian ini yaitu penelitian deskriptif dengan pendekatan cross sectional study yang bertujuan untuk mengetahui gambaran lesi traumatik mukosa mulut pada lansia pengguna GTSL di pantipanti werda Minahasa Induk. Metode pengambilan sampel pada penelitian ini dengan total sampel. Instrumen yang digunakan dalam penelitian ini ialah kuesioner dan alat tulis menulis.

Populasi penelitian ini adalah seluruh lansia di tujuh panti werda di Minahasa Induk dengan jumlah populasi 30 orang lansia yang terdiri dari Panti Sosial Tresna Werda Agape Tondano 5 orang lansia pengguna gigi tiruan, Panti Sosial INA I 2 orang lansia pengguna gigi tiruan, Panti Werda Debora 5 orang lansia pengguna gigi tiruan, Panti Sosial Tresna Werda Yakobus peduli 7 orang lansia pengguna gigi tiruan, Panti Werda Hana 3 orang lansia pengguna gigi tiruan, Panti Sosial Tresna Werda Tabita 2 orang lansia pengguna gigi tiruan, dan Panti Werda Pengasih 6 orang lansia pengguna gigi tiruan. Sampel penelitian yaitu semua lansia yang menggunakan gigi tiruan sebagian lepasan, dengan kriteria inklusi lansia usia 60-80 tahun yang menggunakan GTSL, bersedia menjadi sampel penelitian dan mengisi kuisioner. Kriteria ekslusi yaitu lansia yang sudah tidak mampu untuk diajak komunikasi dengan efektif.

Data yang telah dikumpulkan kemudian dianalisis dengan analisis univariat menggunakan program Microsoft Excel dan disajikan dalam bentuk tabel.

\section{HASIL PENELITIAN}

Jumlah responden yang diwawancarai 30 orang dengan kriteria inklusi kehilangan sebagian gigi di rahang atas dan rahang bawah, atau di rahang atas dan rahang 
bawah yang memakai gigi tiruan sebagian lepasan. Responden sebanyak 30 orang didapatkan dari 7 panti werda yang berada di Kabupaten Minahasa Induk.

Dari hasil penelitian diperoleh jumlah responden terbanyak yaitu usia lansia 75-90 tahun berjumlah 17 responden $(56,67 \%)$, dan responden dengan jumlah terkecil usia remaja 60-74 tahun yaitu 13 responden
$(43,3 \%)$. Jumlah responden yang memakai GTSL berjenis kelamin perempuan lebih banyak dibandingkan laki-laki yaitu 28 orang $(93,3 \%)$ (Tabel 1). Berdasarkan pendidikan jumlah responden terbanyak yaitu responden yang tamat SMA/setara dan SD sebanyak 10 responden $(43,3 \%)$, dan responden dengan jumlah terkecil pendidikan SD sebanyak 7 responden $(8 \%)$.

\section{Gambaran Hasil Penilaian dari Kuesioner}

Tabel 1. Distribusi subjek penelitian berdasarkan jenis kelamin yang mengalami lesi traumatik

\begin{tabular}{|c|c|c|c|c|c|c|}
\hline \multirow{2}{*}{ Jenis kelamin } & \multicolumn{2}{|c|}{ Pernah } & \multicolumn{2}{|c|}{ Tidak } & \multicolumn{2}{|c|}{ Total } \\
\hline & $\mathrm{n}$ & $\%$ & $\mathrm{~N}$ & $\%$ & $\mathrm{n}$ & $\%$ \\
\hline Laki-laki & 2 & 6,9 & 0 & 0 & 2 & 6,7 \\
\hline Perempuan & 27 & 93,10 & 1 & 3,44 & 28 & 93,3 \\
\hline Total & 29 & 100 & 1 & 3,44 & 30 & 100 \\
\hline
\end{tabular}

Tabel 2. Distribusi subjek penelitian berdasarkan pernah atau tidak pernah mengalami lesi traumatik.

\begin{tabular}{ccc}
\hline Lesi Traumatik & $\mathrm{N}$ & $\%$ \\
\hline Pernah & 29 & 96,6 \\
Tidak Pernah & 1 & 3,4 \\
Total & 30 & 100 \\
\hline
\end{tabular}

\section{BAHASAN}

Berdasarkan hasil penelitian subjek penelitian terbanyak pengguna GTSL pernah mengalami lesi traumatik yaitu sebanyak 29 subjek penelitian (93,3\%). Hasil ini sesuai dengan penelitian yang dilakukan oleh Mayvira tentang prevalensi dan distribusi lesi-lesi mukosa mulut pada manusia lanjut usia pengguna gigi tiruan di panti jompo Abdi Darma Asih Binjai Sumatera Utara yang menyatakan bahwa terdapat $97 \%$ lansia terdapat lesi mukosa. ${ }^{17}$
Lansia yang tinggal di panti ini sebagian besar memiliki penyakit sistemik, meskipun begitu dijumpai juga lansia yang tidak memiliki penyakit sistemik, dijumpai lesilesi mukosa mulut. Selain dari penyakit sistemik, obat-obatan yang dikonsumsi sehubungan dengan penyakit sistemik juga turut berperan menimbulkan lesi-lesi mukosa mulut. ${ }^{18}$ Berdasarkan hasil penelitian subjek penelitian terbanyak mengalami lesi traumatik pada lidah yaitu sebanyak 16 subjek penelitian $(55,1 \%)$. 
Tabel 3. Distribusi subjek penelitian berdasarkan lesi traumatik mukosa mulut.

\begin{tabular}{|c|c|c|c|}
\hline \multirow{2}{*}{ Kriteria } & & \multicolumn{2}{|c|}{ Lesi Traumatik } \\
\hline & & $\mathrm{n}$ & $\%$ \\
\hline \multirow{5}{*}{ Lokasi Lesi } & Mukosa Bibir & 9 & 31,0 \\
\hline & Mukosa Pipi & 4 & 13,7 \\
\hline & Lidah & 16 & 55,1 \\
\hline & Gingiva & 0 & 0 \\
\hline & Total & 29 & 100 \\
\hline \multirow{4}{*}{$\begin{array}{c}\text { Penyebab Lesi } \\
\text { Traumatik }\end{array}$} & Dasar/Sayap GTSL & 18 & 62,1 \\
\hline & Kerangka GTSL & 3 & 10,3 \\
\hline & Tepi Plat & 8 & 27,6 \\
\hline & Total & 29 & 100 \\
\hline \multirow{5}{*}{$\begin{array}{l}\text { Frekuensi Waktu } \\
\text { terjadinya lesi }\end{array}$} & 2 Minggu Sekali & 1 & 3,4 \\
\hline & 1 Bulan Sekali & 5 & 17,3 \\
\hline & 6 Bulan Sekali & 3 & 10,4 \\
\hline & Tidak Teratur & 20 & 68,9 \\
\hline & Total & 29 & 100 \\
\hline \multirow{5}{*}{ Cara Penanganan } & Dibiarkan Tanpa Obat & 14 & 48,3 \\
\hline & Mengobati Sendiri & 15 & 51,7 \\
\hline & Ke Dokter Umum & 0 & 0 \\
\hline & Ke Dokter Gigi & 0 & 0 \\
\hline & Total & 29 & 100 \\
\hline \multirow{5}{*}{ Pengobatan Sendiri } & Obat Kumur & 3 & 20 \\
\hline & Obat Topikal & 11 & 73,3 \\
\hline & Minum Obat Analgetik & 1 & 6,7 \\
\hline & Minum Obat Antibiotik & 0 & 0 \\
\hline & Total & 15 & 100 \\
\hline
\end{tabular}

Hal ini sejalan dengan penelitian yang dilakukan oleh Anura tentang yang menyatakan bahwa lokasi lesi traumatik terbanyak ditemukan pada daerah lidah yaitu sebesar $55,1 \%$ akibat penggunaan gigi tiruan. ${ }^{19}$

Mukosa gingiva merupakan mukosa mastikasi dimana epitelnya merupakan epitel berkeratin, dengan vaskularisasi sedang. Jaringan ikat kolagen pada mukosa ini lebih padat, tebal dan teratur dibandingkan dengan jaringan ikat kolagen pada mukosa penutup. Mukosa pipi, bibir dan ventral lidah termasuk dalam mukosa penutup yang sifatnya fleksibel. Epitel pada mukosa ini merupakan epitel skuamosa berlapis yang tidak berkeratin, sedangkan lamina proprianya terdiri dari serat kolagen yang elastis dan retikular. Hal tersebut menyebabkan mukosa pipi, bibir dan ventral lidah lebih rentan terhadap terjadinya lesi saat terjadi trauma. ${ }^{20}$ 
Berdasarkan hasil penelitian ditemukan bahwa penyebab paling banyak terjadinya lesi traumatik pada pengguna GTSL adalah bagian sayap dari GTSL yaitu sebanyak 18 subjek penelitian $(62,1 \%)$. Hal ini sejalan dengan penelitian yang dilakukan oleh Mayvira yang menyatakan bahwa lesi traumatik pada pengguna gigi tiruan biasanya terjadi karena adanya tekanan dari dasar atau sayap gigi tiruan yang tidak pas atau dari kerangka gigi tiruan sebagian. ${ }^{20}$

Bentuk lesi traumatik sesuai dengan penyebabnya, yaitu memanjang, biasanya memanjang soliter dan ukurannya bervariasi. Permukaannya biasanya tertutup selaput putih kekuningan dan dikelilingi tepi yang lebih tinggi dan keras pada perabaan. ${ }^{17}$

Distribusi lesi traumatik berdasarkan frekuensi terjadinya menunjukkan bahwa sebagian besar responden menyatakan lesi traumatik terjadi tidak teratur. Terjadinya lesi traumatik tergantung pada seberapa rentan mukosa mulut seseorang dan seberapa baik komponen alat yang digunakan. $^{10,5}$ Menurut penelitian saat terjadi gesekan antara komponen GTSL dengan mukosa mulut akan terjadi perubahan sel epitel mukosa. Perubahan tersebut merupakan bagian dari proses penyesuaian mukosa dengan alat. ${ }^{5,6}$ Penelitian sebelumnya menemukan bahwa kontak yang terjadi antara alat GTSL dengan mukosa menyebabkan berkurangnya nukleus dan sitoplasma, yang secara histologi reaksi selular ini dikenal dengan atrofi. Atrofi merupakan respon adaptif yang dapat menyebabkan berkurangnya suplai darah, nutrisi yang tidak adekuat, hipoksia dan tekanan. Terkait dengan efek-efek tersebut, atrofi sel dapat meningkat sampai pada kondisi dimana sel terluka dan mati. ${ }^{21}$

Hasil penelitian berdasarkan cara penanganan lesi ulseratif menunjukkan bahwa $48,3 \%$ subjek penelitian membiarkan tanpa perawatan terhadap ulkus yang dialami. Hal ini dikarenakan lesitraumatik biasanya dapat sembuh sendiri tanpa perawatan dalam kurun waktu
7 - 14 hari. Selain itu juga, banyak orang menganggap lesitraumatik bukan masalah yang serius sehingga penanganan lesitraumatik masih dianggap tidak perlu kecuali lesi traumatik menyebabkan ketidaknyamanan yang besar saat beraktivitas. $^{21}$

Sebanyak $51,7 \%$ subjek penelitian melakukan perawatan dengan mengobati sendiri dan hanya sebagian kecil yang pergi ke dokter gigi. Hal ini sesuai dengan yang dikutip dari Menteri Kesehatan Republik Indonesia yang menyatakan bahwa perilaku masyarakat Indonesia dalam mengobati penyakit mulutnya yaitu hanya dengan mengobatinya sendiri dan jarang pergi ke dokter. $^{22}$ Penanganan lesi traumatik ditujukan untuk mempercepat sembuhnya lesi, mengurangi rasa sakit, atau mencegah terjadinya infeksi atau lebih parahnya lesi. $^{23}$ Subjek penelitian paling banyak menggunakan obat topikal yaitu $73,3 \%$ sedangkan persentase penggunaan obat minum sangat kecil. Hal ini serupa dengan yang dikutip dari Gupta dkk.dimana obat yang paling banyak digunakan untuk mengobati ulserasi pada mulut yaitu topikal steroid $(45 \%)$ sedangkan yang paling sedikit yaitu pemakaian antibiotik dan analgesik $(19 \%){ }^{24}$

Hasil penelitian ini juga menunjukkan bahwa subjek penelitian lebih banyak memilih menggunakan obat topikal daripada obat kumur. Hal ini dapat disebabkan oleh tingkat efektivitas dalam penyembuhan lesi, dimana sesuai dengan penelitian bahwa penggunaan obat topikal lebih efektif dibandingkan obat kumur, baik dalam mengurangi intensitas rasa sakit maupun dalam proses penyembuhan ulkus. $^{25}$

Penggunaan topikal kortikosteroid dianjurkan untuk pengobatan terhadap ulserasi pada mukosa mulut. Topikal kortikosteroid berfungsi sebagai agen antiinflamasi. Topikal kortikosteroid dapat berupa triamcinolone acetonide $0,1 \%$, kenalog in orabase, salep hydrocortisone acetate $1 \%$ dan salep bethamethasone dipropionate $0,05 \% .^{26}$ 


\section{SIMPULAN}

Berdasarkan gambaran lesi traumatik mukosa mulut pada lansia pengguna gigi tiruan sebagian lepasan di panti werda Kabupaten Minahasa menunjukkan sebagian besar pernah mengalami lesi traumatik akibat penggunaan gigi tiruan sebagian lepasan.

\section{SARAN}

1. Bagi institusi kesehatan agar dilakukan peningkatan pelayanan kesehatan gigi dan mulut terutama bagi para lansia serta melakukan penyuluhan tentang pentingnya dan cara merawat kebersihan gigi dan mulut terutama pada lansia pengguna GTSL.

2. Bagi masyarakat Agar masyarakat terutama lansia lebih memperhatikan kesehatan gigi dan mulut dan tidak membiarkan begitu saja apabila terjadi lesi traumatik.

\section{DAFTAR PUSTAKA}

1. John W. The strange story of false teeth. London: Routledge \& Kegan Paul. 1968. p.48.

2. Dinarto, Murjiah. 2002. Tim Nutrisi. Majalah Gizi Medik Indonesia Vol 1 No. 1 Februari. Jakarta.

3. Sunariani J, Yuliati, Aflah B. Perbedaan Persepsi Pengecap Rasa Asin Antara Usia Subur Dan Usia Lanjut. Majalah Ilmu Faal Indonesia Vol. 6/3/200.

4. Shotwell J. Classification And Compontnts of Removable Partial Dentures. University of Michigan [serial inline] 2008; [cited 5 Mei 2013] Available from: URL: https://open.umich.edu/sites/default/file s/1029/JShotwell Week6.pdf

5. Langlais R, Miller C. Atlas Berwarna: kelainan Rongga Mulut yang Lazim. Jakarta: Hipokrates. 2007. p. 40-2.

6. Jayasingha $\mathbf{R}$, et al. impact of Marginal Contact Of Removable Acrylic Partial Denture On Periodontal parameters. International Journal of Reaserch In Medical and Health Sciences April 2013; 1(3): 1-11.

7. Petridish H, Hempton T. Periodontal consideration In removable partial denture Treatment: A review of the
Literature. The International Journal of Prosthodontics 2001; 14(2): 164-72.

8. Applegete. Essensial of removable partial denture prosthesis, $2^{\text {nd }}$ ed. Philadelphia: W.B Saunders. 1960. p..40.

9. Whitney E. Oral Lesion: When to Treat, Biopsy, or Ignore. The Canadian Journal of Diagnosis October 2009; 1(2): 69-71.

10. Nugroho W. Komunikasi dalam keperawatan Gerontik. Jakarta: EGC; 2009. p. 5.

11. Ratmini N, Arifin. Hubungan Kesehatan mulut dengan kualitas hidup lansia. Jurnal ilmu gizi Agustus 2011; 2(2): $139-47$.

12. Kristiana D, Niani A, Gunudi A. Tingkatan Kepuasan Pasien Gigitiruan Sebagaian Lepasan Di Rumah Sakit Gigi Dan Mulut Fakultas Kedokteran Gigi Universitas Jember. Jurnal kedokteran gigi Unej 2011; 8(2): 10813.

13. Shah A, Ahmad TJ. Oral Mucosal Lesion in Complete Denture Wearers. Journal of Pakistan Association of Dermatologist 2011; 21(3): 170-3.

14. Donald Y, Burns J. Common Oral Mucosal lesion in Adults. American Family Physician December 1991; 44(6). 2043-50.

15. Gunadi HA, Margo A, Burhan LK, Suryatenggara F, Setiabudi I. editor. Buku ajar geligi tiruan sebagian lepasan. Jakarta: Hipokrates;2012. p.12-3,33-41

16. Kenneth S, Joseph E. Grasso. Barrack. The complete denture prosthesis: Clinical and Laboratory Applications Insertion, Patient Adaptation, and PostInsertion care. [cited 12 mei 2013] Available from: URL: http://www, dentalcare.com/media/enUS/education/ce109.pdf

17. Zain RB, Ikeda N, Razak IA, Axell T, Majid ZA, Gupta PC, Yacoob M. A national epidemiological survey of oral mucosal lesion in malaysia. Community oral Dent Epidemiologi 1997; 25: 379.

18. Avery JK. Oral development and histology 3rd ed. New York: Thieme; 2001. p. 248-273.

19. Ernawati DS. Kelainan jaringan lunak rongga mulut akibat proses dan 
treatment. 10th ed. Ontario: BC Decker Inc, 2003: 94,126, 612.

20. Anriyani. Pemakaian dan kualitas gigitiruan yang digunakan masyarakat kelurahan padang bulan kecamatan medan baru. Dentika Dental Journal 2006; 2(2): 108-13.

21. Keputusan Menteri Kesehatan Republik Indonesia. Depkes RI [serial online] 2005 [cited 2013 Aug 7]. Available from:

URL:

http://perpustakaan.depkes.go.id:8180/ bitstream//123456789/1290/1/KMK14 15-1005.pdf

22. Scully C, Porter S, Porter SR. Orofacial Disease: Update for the dental clinical team. Barcelona: Churchill Livingstone; 2003. p. 11-2.

23. Gupta L, Chandavarkar V, Galgali SR, Mishra M. Clorhexidine, a medicine for all the oral diseases. GJMEDPH [serial online] 2012 [cited 2013 Oct 6]; 1(2): 43-8. Available from: URL: http://www.aften-hilfe.de/wpcontent/uploads/amlexanosapthasol.pdf

24. Mostafa AAE, Ibrahem AEM. Management of aphthous ulceration with topical quercetin. CDJ [serial online] 2009 [cited 2013 Oct 6]; 25(1): 9-15. Available from: URL: http://dentistry.cu.edu.eg/Files/CDJ/20 09/January\%202009/9-15-2.pdf

25. Savage NW, McCullough MJ. Topical corticosteroids in dental practice. Aus dent $\mathbf{J}$ [serial online] 2005 [cited 2013 Aug 1]; 50(2): 40-4. Available from: URL:

http://onlinelibrary.wiley.com/doi/10.1 111/j.1834-7819.2005.tb00385.x/pdf. 